\title{
Androstenedione rhythms in saliva in congenital adrenal hyperplasia
}

\author{
M C YOUNG, R F WALKER, D RIAD-FAHMY, AND I A HUGHES \\ Department of Child Health and Tenovus Institute, University of Wales College of Medicine, Cardiff
}

SUMMARY Serial samples of saliva were collected at home by 17 patients being treated for congenital adrenal hyperplasia to determine the circadian rhythm of androstenedione as an index of therapeutic control. Single samples of blood for measurement of plasma testosterone, $170 \mathrm{H}$-progesterone, and androstenedione concentrations were collected from these and a further seven patients for comparison. Plasma androstenedione concentrations showed a close correlation with plasma concentrations of $170 \mathrm{H}$-progesterone and testosterone. There was a strong correlation between the salivary androstenedione profiles and plasma testosterone concentrations in pubertal girls. Concentrations of androstenedione in saliva decreased during the day but remained raised at each sampling time in relation to plasma testosterone concentrations. Salivary androstenedione profiles are shown as nomograms to distinguish the degree of therapeutic control. The concentration of androstenedione, measured in plasma or saliva, is an alternative marker to monitor control of treatment in congenital adrenal hyperplasia. The measurement in saliva is a useful index of androgen production when blood sampling is difficult.

Measurements of $170 \mathrm{H}$-progesterone in blood spot and saliva are useful to monitor treatment in patients with congenital adrenal hyperplasia. ${ }^{1}$ The measurement of plasma androstenedione concentrations has also been suggested. ${ }^{2}$ Androstenedione is a weak adrenal androgen and, unlike $170 \mathrm{H}$ progesterone, single measurements are less affected by wide circadian variations in plasma concentrations.

This study reports the use of salivary androstenedione profiles to monitor treatment in congenital adrenal hyperplasia. The results are compared with single random measurements of plasma androstenedione, testosterone, and $170 \mathrm{H}$-progesterone as indices of the degree of control.

\section{Patients and methods}

Twenty four patients aged 2 to 22 years with congenital adrenal hyperplasia caused by 21hydroxylase deficiency, provided data for the study. Androstenedione profiles were measured in 17 patients 11 of whom were female over a two year period. Samples of saliva were collected at home at $0800,1200,1800$, and 2200 hours, on two consecutive weekend days. A profile represents andro- stenedione concentrations during one day. The dose of glucocorticoid, given either as hydrocortisone in divided doses or as dexamethasone once daily, was adjusted according to clinical indices of control, and single random measurements of plasma $170 \mathrm{H}$ progesterone, testosterone, androstenedione concentrations, and where appropriate, plasma renin activity. Androstenedione profiles in two pubertal male patients were excluded from the analysis because of predominant testicular production at this age. The remaining 11 pubertal female patients and four prepubertal children provided a total of 44 profiles (28 and 16, respectively) for analysis. Data from an additional 11 incomplete profiles were also included in the analysis where appropriate.

The result of each salivary androstenedione profile was compared with the plasma testosterone concentration that had been measured in a morning blood sample collected at a recent clinic. Data from pubertal female patients and prepubertal children were analysed separately according to the normal testosterone values for these ages-that is, $0 \cdot 3-2 \cdot 5$ $\mathrm{nmol} / \mathrm{l}$ and $<0.5 \mathrm{nmol} / \mathrm{l}$, respectively. ${ }^{2-4}$

Plasma testosterone,${ }^{5}$ plasma $170 \mathrm{H}$-progesterone ${ }^{6}$ and plasma and salivary androstenedione ${ }^{7}$ concentrations were measured by radioimmunoassay. The 
results were analysed by non-parametric statistical methods as the data were generally not normally distributed. The methods are stated where appropriate.

\section{Results}

Fig 1 shows the association between simultaneous measurements of plasma androstenedione and testosterone concentrations in patients with treated congenital adrenal hyperplasia. There was a strong correlation $(r=0.9, p<0.001)$, with values being lowest in prepubertal children. Fig 2 shows a similar correlation between plasma androstenedione and $170 \mathrm{H}$-progesterone concentrations $(r=0 \cdot 8$, $\mathrm{p}<0 \cdot 001)$.

There was a circadian variation in salivary androstenedione concentrations in all 17 patients who provided profiles. The concentration of androstenedione at 0800 hours was usually greater than

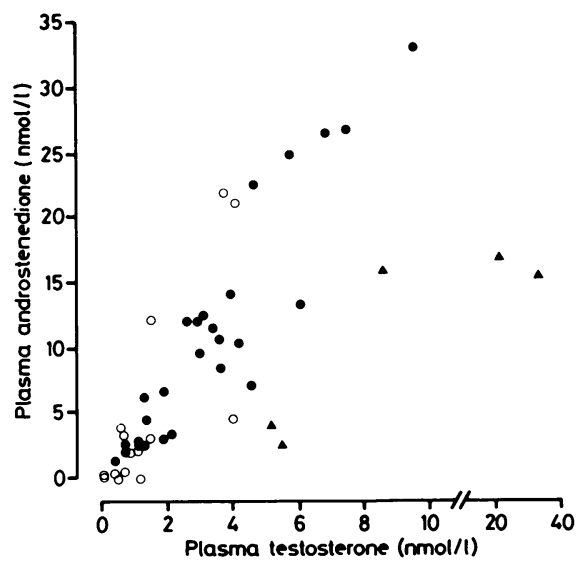

Fig 1 Association between simultaneous measurements of plasma androstenedione and testosterone concentrations in patients being treated for congenital adrenal hyperplasia. $\mathrm{O}=$ prepubertal patients $(n=7) ; \bigcirc=$ pubertal female patients $(n=13)$; and $\mathbf{\Delta}=$ pubertal male patients $(n=3)$.

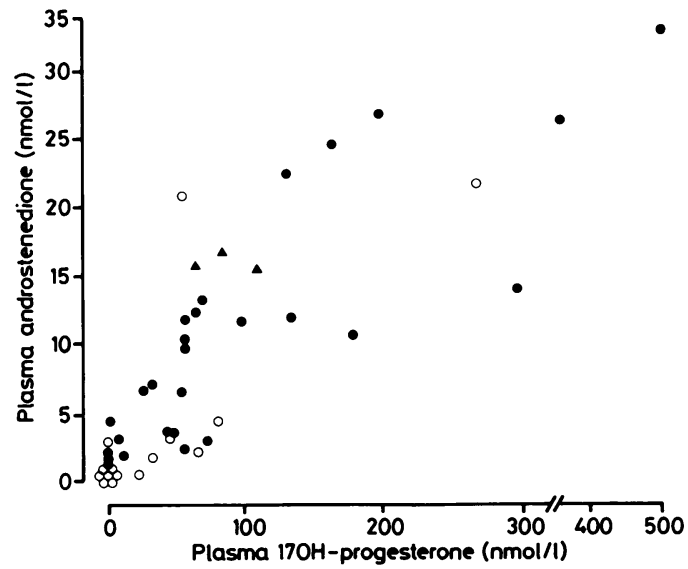

Fig 2 Association between simultaneous measurements of plasma androstenedione and plasma $170 \mathrm{H}$-progesterone in patients being treated for congenital adrenal hyperplasia $;=$ prepubertal patients $(n=7) ; \bigcirc=$ pubertal female patients $(n=13)$; and $\mathbf{\Delta}=$ pubertal male patients $(n=3)$.

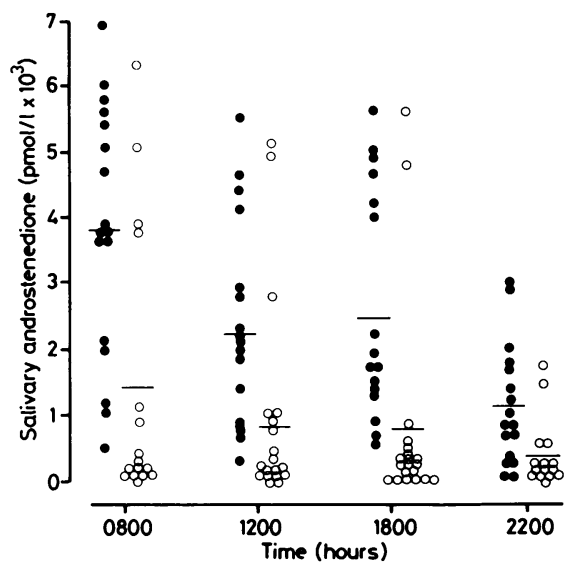

Fig 3 Concentrations of androstenedione in saliva in relation to sampling time and range of plasma testosterone concentrations. Bars $=$ mean values $; \mathbf{O}=$ plasma testosterone $>2.5 \mathrm{nmol} / \mathrm{l} ;$ and $\mathrm{O}=$ plasma testosterone $<2.5 \mathrm{nmol} / \mathrm{l}$.

Table 1 Salivary androstenedione and plasma testosterone concentrations in pubertal females

\begin{tabular}{|c|c|c|c|c|c|c|c|c|}
\hline & \multicolumn{8}{|c|}{ Sampling time (hours) } \\
\hline & \multicolumn{2}{|l|}{0800} & \multicolumn{2}{|l|}{1200} & \multicolumn{2}{|l|}{1800} & \multicolumn{2}{|l|}{2200} \\
\hline & ${ }^{*} T I$ & $T 2$ & $T I$ & $T 2$ & $T 1$ & $T 2$ & $T 1$ & $T 2$ \\
\hline No of observations & 17 & 16 & 17 & 21 & 18 & 20 & 17 & 19 \\
\hline \multicolumn{9}{|l|}{$\begin{array}{l}\text { Salivary androstenedione } \\
(\mathrm{pmol} / \mathrm{l}) \text { : }\end{array}$} \\
\hline Mean & 3836 & 1460 & 2344 & 839 & 2484 & 804 & 1145 & 429 \\
\hline Range & $540-6900$ & $69-6309$ & $330-5500$ & $66-5112$ & $583-5600$ & $82-5628$ & $80-3000$ & $61-1823$ \\
\hline
\end{tabular}

*T1-plasma testosterone concentration $>2.5 \mathrm{nmol} / \mathrm{l} ; \mathrm{T} 2$ - plasma testosterone concentration $<2.5 \mathrm{nmol} / \mathrm{l}$. 
that at 2200 hours, but a consistent fall in androstenedione concentrations at each sampling time was seen in only one third of the profiles. Fig 3 and table 1 show the results of salivary androstenedione profiles in pubertal female patients. The profiles were subdivided according to testosterone values greater or less than $2.5 \mathrm{nmol} / \mathrm{l}$. Salivary androstenedione values in both groups gradually fell during the day to their lowest values at 2200 hours. Increased plasma testosterone concentrations were generally associated with high salivary androstenedione concentrations at each sampling time. Although there was some overlap in androstenedione values in the two groups, mean salivary androstenedione concentrations were significantly higher at all sampling times in those patients with plasma testosterone values greater than $2.5 \mathrm{nmol} / \mathrm{l}$ $(\mathrm{p}<0.001$, Mann-Whitney U test). The positive correlation between salivary androstenedione values at 2200 hours and plasma testosterone concentrations is shown in Fig 4. A similar association was seen at each sampling time (table 2). The results may be used to derive values for salivary androstenedione concentrations that distinguish patients with normal or raised plasma testosterone concentrations. The nomogram (fig 5) indicates how salivary androstenedione profiles may be used to monitor the adequacy of treatment in pubertal females with congenital adrenal hyperplasia.

Salivary androstenedione profiles were available for analysis in only four prepubertal children. There

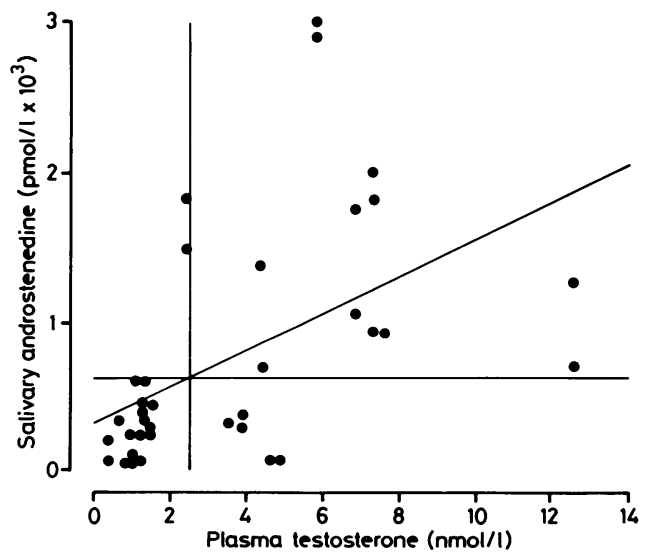

Fig 4 Association between saliva androstenedione concentrations and plasma testosterone in pubertal female patients at 2200 hours. Vertical line denotes plasma testosterone concentration of $2.5 \mathrm{nmolll}$, and horizontal intersect of this and regression line denotes androstenedione concentration in saliva that distinguishes good and poor control. was a correlation between salivary androstenedione and plasma testosterone concentrations at every sampling time except 1200 hours (table 3 and fig 6). Fig 7 and table 3 show how salivary androstenedione profiles can distinguish adequate from poor control

Table 2 Salivary androstenedione concentrations that differentiate the degree of control in pubertal female patients at each sampling time according to plasma testosterone concentration of $2 \cdot 5 \mathrm{nmol} / \mathrm{l}$

\begin{tabular}{lllll}
\hline \multicolumn{5}{c}{ Sampling time (hours) } \\
\cline { 2 - 5 } & $\begin{array}{l}0800 \\
(n=33)\end{array}$ & $\begin{array}{l}1200 \\
(n=38)\end{array}$ & $\begin{array}{l}1800 \\
(n=38)\end{array}$ & $\begin{array}{l}2200 \\
(n=36)\end{array}$ \\
\hline $\begin{array}{l}\text { Spearman's rank } \\
\text { correlation coefficient (r) }\end{array}$ & $\begin{array}{l}0.70 \\
\text { Value }\end{array}$ & 0.71 & 0.78 & 0.70 \\
$\begin{array}{c}\text { Androstenedione } \\
\text { concentration (pmol/l) }\end{array}$ & 2150 & 1270 & 1300 & 620 \\
\hline
\end{tabular}

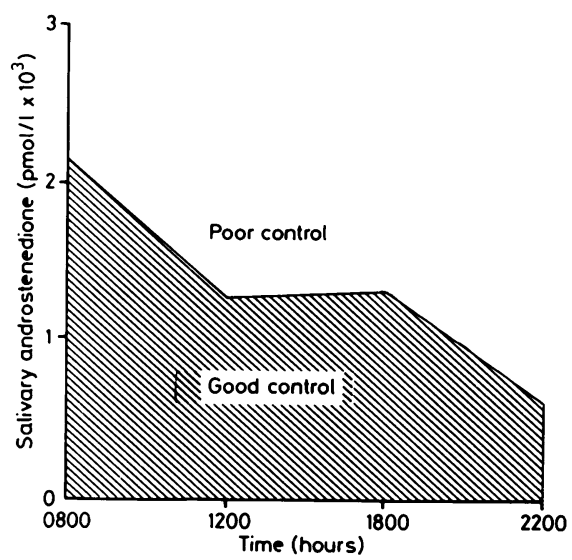

Fig 5 Nomogram to monitor control in pubertal female patients with congenital adrenal hyperplasia using androstenedione profiles in saliva. Area labelled "good control" is associated with plasma testosterone concentrations within normal range of $0 \cdot 3-2 \cdot 5 \mathrm{nmol} / \mathrm{l}$.

Table 3 Salivary androstenedione concentrations that differentiate the degree of control in prepubertal children at each sampling time according to plasma testosterone concentration of $0.5 \mathrm{nmol} / \mathrm{l}$

\begin{tabular}{|c|c|c|c|c|}
\hline & \multicolumn{4}{|c|}{ Sampling time (hours) } \\
\hline & $\begin{array}{l}0800 \\
(n=15)\end{array}$ & $\begin{array}{l}1200 \\
(n=16)\end{array}$ & $\begin{array}{l}1800 \\
(n=16)\end{array}$ & $\begin{array}{l}2200 \\
(n=13)\end{array}$ \\
\hline $\begin{array}{l}\text { Spearman`s rank corrclation } \\
\text { coefficient }(r)\end{array}$ & 0.78 & $0 \cdot 36$ & $0 \cdot 85$ & 0.70 \\
\hline p Valuc & $<0 \cdot(001$ & NS & $<0.0001$ & $1<0 \cdot 001$ \\
\hline $\begin{array}{l}\text { Androstenedione } \\
\text { concentration }(\mathrm{pmol} / \mathrm{l})\end{array}$ & 1500 & 760 & 640 & 260 \\
\hline
\end{tabular}




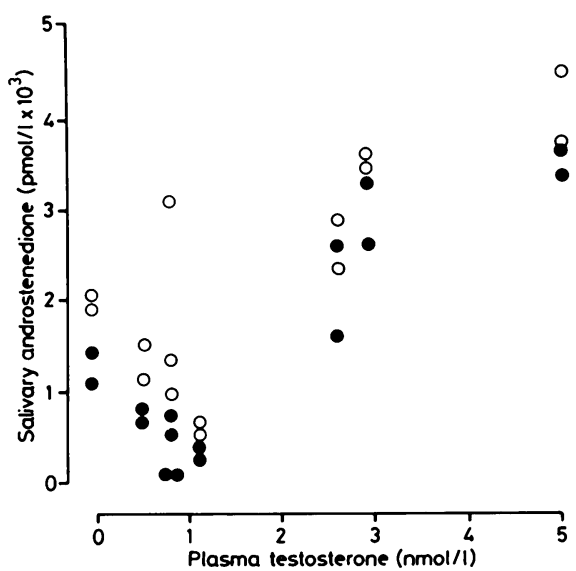

Fig 6 Association between saliva androstenedione concentrations at 0800 hours $(\bigcirc)$ and 1800 hours (O) and plasma testosterone concentrations in prepubertal children.

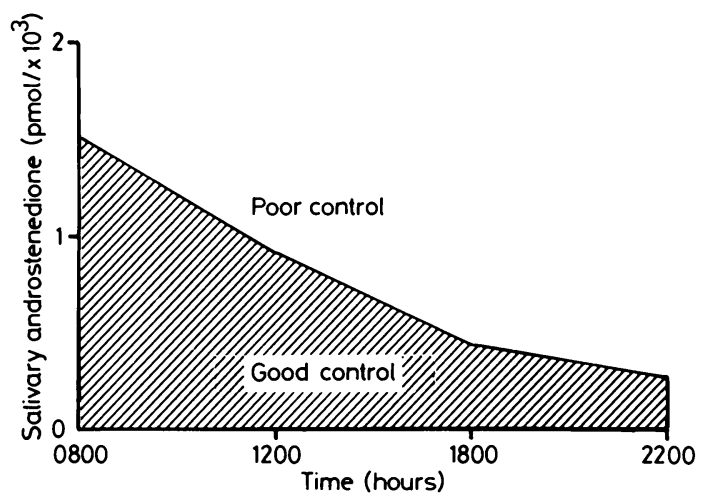

Fig 7 Nomogram to monitor control in prepubertal children with congenital adrenal hyperplasia using androstenedione profiles in saliva. Area labelled "good control" is associated with plasma testosterone concentrations of less than $0.5 \mathrm{nmol} / \mathrm{l}$.

in prepubertal children with congenital adrenal hyperplasia.

\section{Discussion}

Single, random measurements of steroids, particularly $170 \mathrm{H}$-progesterone, can be difficult to interpret when used to monitor treatment of congenital adrenal hyperplasia. Testosterone has been used most frequently as a single marker but in infant and pubertal male patients the concentration of steroid reflects testicular rather than adrenal androgen production. Measurement of plasma androstenedione concentration has been advocated as a useful alternative. ${ }^{2}$ This study confirms the strong association between simultaneous measurements of plasma testosterone, androstenedione, and $170 \mathrm{H}$ progesterone concentrations. ${ }^{8}$ Korth-Schutz et $a l^{2}$ reported that poor control of congenital adrenal hyperplasia was associated with increased plasma testosterone and androstenedione concentrations. They concluded that androstenedione concentrations were more accurate in distinguishing between patients in good and poor control.

We have shown an association between salivary androstenedione and plasma testosterone concentrations. There was a circadian rhythm in androstenedione concentrations in treated patients with congenital adrenal hyperplasia irrespective of age, sex, or stage of puberty. The magnitude of the circadian rhythm was less than for $170 \mathrm{H}-$ progesterone $^{1}$ but the accuracy of the salivary androstenedione nomogram for predicting adequacy of control in pubertal girls was still $90 \%$. The nomogram was less discriminant as only two groups (adequate and poor control) could be identified. Only a small number of profiles from prepubertal children were available for analysis. There was a positive correlation between salivary androstenedione and plasma testosterone concentrations at most sampling times. The nomogram (fig 7) provides only an approximate guide to the control of treatment until the values for salivary androstenedione that will distinguish degrees of control are more precisely defined.

Androstenedione is a weak androgen which is secreted by both the adrenal glands and the gonads. Measurement of it in patients with congenital adrenal hyperplasia provides a useful marker of excessive adrenal androgen production, particularly in pubertal male patients. Salivary androstenedione profiles show a circadian rhythm that is closely associated with plasma testosterone concentrations, particularly in pubertal female patients. The profiles may be used alone, or in conjunction with $170 \mathrm{H}$ progesterone to monitor androgen production.' When the profiles of both steroids are used it is possible to achieve a sensitive degree of control and an index of androgen production in those patients who are reluctant to have blood samples taken.

\section{References}

1 Young MC, Robinson JA, Read GF, Riad-Fahmy D, Hughes 1A. 170) H-progesterone rhythms in congenital adrenal hyperplasia. Arch Dis Child 1988:63:617-23.

2 Korth-Shutz S, Virdis R. Saenger P. Chow DM. Levine LS, New MI. Serum androgens as a continuing index of adequacy of treatment of congenital adrenal hyperplasia. J Clin Endocrinol Metab 1978;46:452-8. 
3 Sizonenko PC, Paunier L. Hormonal changes in puberty III: Correlation of plasma dehydroepiandrosterone, testosterone FSH, and LH with stages of puberty and bone age in normal boys and girls and in patients with Addison's discase or hypogonadism or with premature or late adrenarche. $J$ Clin Endocrinol Metab 1975;41:894-904.

+ Ducharme JR, Forest MG, De Peretti E, Sempe M, Collu R, Bertrand $\mathrm{J}$. Plasma adrenal and gonadal sex steroids in human pubertal development. J Clin Endocrinol Metab 1976;42: 468-76.

${ }^{5}$ Dyas J, Read GF, Riad-Fahmy D. A simple robust assay for testosterone in male plasma using an ${ }^{125}$ I-radioligand and a solid-phase separation technique. Ann Clin Biochem 1970;16:325-31.

'Dyas J, Read GF, Guha-Maulik T, Hughes IA, Riad-Fahmy D. A rapid assay for $170 \mathrm{H}$-progesterone in plasma, saliva and amniotic fluid using a magnetisable solid-phase antiserum. $A n n$ Clin Biochem 1984;21:5918-25.

7 Turkes AO, Read GF. Determination of androstenedione in saliva. In: Read GF, Riad-Fahmy D, Walker RF, Griffiths K. eds. Immunoassays of steroids in saliva. Cardiff: Alpha Omega Publishing, 1982:260-70.

$\checkmark$ Hughes IA, Winter JSD. The relationships between serum concentrations of $170 \mathrm{H}$-progesterone and other serum and urinary steroids in patients with congenital adrenal hyperplasia. $J$ Clin Endocrinol Metab 1978:49:98-104.

Correspondence to Dr IA Hughes, Department of Child Health, University of Wales College of Medicine, Heath Park, Cardiff CF4 $4 X N$.

Accepted 27 October 1987 